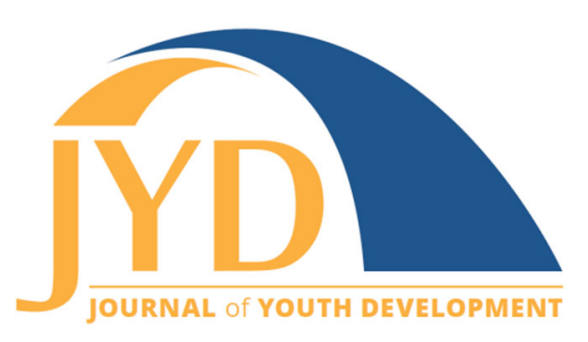

http://jyd.pitt.edu/ | Vol. 15 Issue 5 DOI 10.5195/jyd.2020.761 | ISSN 2325-4017 (online)

\title{
Lessons Learned: Implementing the Shaping Healthy Choices Program With Teenagers as Teachers
}

\author{
Lyndsey D. Ruiz \\ Center for Nutrition in Schools, Department of Nutrition, University of California, Davis \\ Idruiz@ucdavis.edu \\ Kelley M. Brian \\ CalFresh Healthy Living, University of California \\ kmbrian@ucdavis.edu

\section{Rachel E. Scherr} \\ Center for Nutrition in Schools, Department of Nutrition, University of California, Davis \\ rescherr@ucdavis.edu
}

\begin{abstract}
One approach that has been successful at improving youth health outcomes is the Shaping Healthy Choices Program, which features garden- and cooking-demonstration-based nutrition education curricula. The objective of this study was to assess the feasibility of implementing Shaping Healthy Choices Program curricula in 4-H using a teenagers as cross-age teachers approach. A teenagers as cross-age teachers model was employed to educate younger youth using the evidence-based curricula in 2 projects, each lasting 6 months over a 2-year period. Teenage teachers completed an initial 2-day training and reflection-on-action discussions following each educational session. Fidelity observations were collected to assess how well the curricula were delivered by teenage teachers. With a goal of $80 \%$, overall fidelity was low (45\%) and teenage teachers were able to deliver only the procedure component of the lessons with adequate average fidelity (84.6\%). Poor participant attendance hindered presentation of additional data. Findings from this study suggest a need for more extensive and specific training for teenage teachers to implement the Shaping Healthy Choices Program.
\end{abstract}

Key words: cross-age teaching, teenagers as teachers, nutrition education, garden-based education

(cc) EY New articles in this journal are licensed under a Creative Commons Attribution 4.0 License. This journal is published by the University Library System, University of Pittsburgh and is cosponsored by the University of Pittsburgh Press. The Journal of Youth Development is the official peer-reviewed publication of the National Association of Extension 4-H Youth Development Professionals and the National AfterSchool Association. 


\section{SHCP With Teen Teachers}

\section{Introduction}

Childhood and adolescent overweight and obesity is an epidemic in the United States with prevalence continuously increasing over the last 35 years (Fryar et al., 2018). As of 2016, $35.1 \%$ of youth aged 2 to 19 years were classified as overweight or obese, with an overweight rate of $16.6 \%$ and an obesity rate of $18.5 \%$ (Fryar et al., 2018). For youth, obesity tends to increase with age, as adolescents aged 12 to 19 years have the highest rates (Fryar et al., 2018). These rates are concerning because childhood obesity is associated with increased risk for adulthood chronic diseases (Ajala et al., 2017; Faienza et al., 2016; Kim et al., 2017; Singh et al., 2008). One possible explanation for the elevated prevalence of obesity is that youth typically have poor overall diet quality (Banfield et al., 2016; Thomson et al., 2019). This is further compounded by youth tending to not meet recommendations for fruit and vegetable consumption (Banfield et al., 2016; Thomson et al., 2019). With this, one potential approach to reducing youth obesity is increasing fruit and vegetable consumption. It has been suggested that integrated comprehensive nutrition programs are most effective for improving youth health (Hayes et al., 2018).

One project aligned with youth obesity prevention tactics is the Shaping Healthy Choices Program (SHCP), which is a comprehensive, multi-component program aimed at improving youth nutrition and health outcomes (Scherr et al., 2014). The SHCP features garden-enhanced nutrition curricula (Brian et al., 2015; Linnell et al., 2015) that were designed using social cognitive theory (Bandura, 1986) and constructivism (Fosnot, 2013) as theoretical frameworks. The curricula feature lessons and cooking demonstrations that follow the 5-Step Experiential Learning Cycle (Kolb, 2015; Training Technologies for Experiential Learning Activities [ Training Technologies], 1998) to educate youth about foods grown around the world, cardiovascular health, general nutrition, and consumerism (Brian et al., 2015; Linnell et al., 2015). In addition to nutrition education, the SHCP promotes youth well-being through school-wide efforts to increase fruit and vegetable consumption and establish school-site wellness committees (Scherr et al., 2014). The SHCP has been evaluated and was found to significantly improve youth body mass index percentiles; nutrition knowledge; physical activity behaviors; and vegetable availability, identification, and consumption in upper elementary-aged youth (Fetter et al., 2018; Scherr et al., 2017; Taylor et al., 2017). These results were observed when the curricula were implemented with high fidelity (Bergman et al., 2018). Fidelity has been defined as "the extent to which the critical components of an intended program are present when that program is enacted" (Century et al., 2010). Assessment of fidelity can be carried out utilizing a variety of methods and entails evaluation of both adherence to the intended program and competence of 


\section{SHCP With Teen Teachers}

the facilitators (Breitenstein et al., 2010; Harn et al., 2013). It is important to assess fidelity in different interventions and programs to provide context for participant outcomes (Breitenstein et al., 2010; Century et al., 2010; Durlak \& DuPre, 2008; Gearing et al., 2011; Mowbray et al., 2003).

The SHCP has shown success at improving youth health status. However, the program curricula have only been implemented using one method with trained adult educators delivering nutrition lessons in traditional classroom settings. To expand its reach, the SHCP should thus be implemented more broadly in out-of-school settings, such as within the 4-H Youth Development Program (4-H). The 4-H program is well-established nationwide and features enrichment programs and opportunities aimed at supporting child and adolescent development (National 4-H Council). The 4-H program frequently delivers enrichment in a variety of subjects utilizing teenagers as cross-age teachers for younger youth. Cross-age teaching allows for teenagers to become specially trained to deliver a specific curriculum to youth typically 2 or 3 years younger than themselves (Murdock et al., 2003). It has been found that teenagers can be effective teachers when provided adequate resources and support (Lee \& Murdock, 2001). To ensure the success of the teenagers-as-teachers model, Lee and Murdock (2001) suggested that programs be designed including 10 essential elements:

- dedicated adults who support teenagers,

- active teenager recruitment,

- strong curriculum,

- initial teenager training,

- ongoing training and support,

- attention to details,

- recognition and reward,

- team building,

- setting teenagers up for success, and

- feedback and evaluation.

Cross-age teaching is not only beneficial for younger youth, but also provides educational, developmental, and emotional benefits for teenage teachers (Murdock et al., 2003; Shanahan, 2015; Weybright et al., 2016; Worker et al., 2018). In nutrition education programs specifically, use of teenage teachers can be just as effective as-or in some regards even more effective than-adult educators (Smith, 2011). Therefore, the objective of this study was to assess the 


\section{SHCP With Teen Teachers}

feasibility of implementing the SHCP curricula in 4-H using a teenagers as cross-age teachers approach.

\section{Methods}

This project was conducted twice over 2 years starting in October 2016 and ending June 2018. Teenagers aged 14 to 18 years and younger youth ages 9 to 13 years were recruited from existing 4-H clubs, local schools, and other community-based programs in a rural Northern California community. For the $1^{\text {st }}$ year, teenagers were trained in an initial 2-day, 10-hour training to become cross-age teachers. The $1^{\text {st }}$ day of training included team building activities to help teenagers become acquainted with fellow teenage teachers; an introduction to youth developmental stages and learning styles; an overview of the SHCP curricula and intended pedagogical approach; and a brief demonstration of one lesson. The $2^{\text {nd }}$ day of training included a more in-depth demonstration of how to facilitate inquiry-based and experiential lessons using another lesson from the SHCP curricula. This type of modeling was provided only at the initial training so that fidelity to the curricula given this amount of training could be assessed. The training in the $2^{\text {nd }}$ year was very similar, but also included returning teenage teachers modeling curricula lessons. The $1^{\text {st }}$ implementation year was utilized for a feasibility study to determine whether teenagers could be effective facilitators for an adapted version of the SHCP. The $2^{\text {nd }}$ implementation year was intended to determine whether the program could be sustained within the participating $4-\mathrm{H}$ club.

Educational sessions with younger youth were held about twice per month for 6 months and met on Sunday afternoons for 90 minutes, as chosen by participants and their parents. Educational sessions were held at a local community center and nearby community garden. These spaces were chosen in an effort to connect youth with their community and increase civic engagement, which is purported to have beneficial effects on adolescent development (Smetana et al., 2006). The SHCP garden-enhanced nutrition curriculum Discovering Healthy Choices (Linnell et al., 2015) was adapted for implementation in an out-of-school setting. The accompanying cooking demonstration-based curriculum Cooking Up Healthy Choices (Brian et al., 2015) was unmodified for this implementation. Teenage teachers volunteered to either lead or assist with facilitation prior to each educational session. Remaining teenage teachers not facilitating the lesson participated in the lesson activities as their own group separate from younger youth groups. Following lesson activities, 15 minutes were allotted for teenage teachers and project staff to complete both written and oral reflection-on-action discussions 


\section{SHCP With Teen Teachers}

using a plus/delta format, as previously utilized by Linnell et al. (2016). For these discussions, teenage teachers were openly prompted to describe features of the implementation that went well and should be continued for subsequent lessons (plus), as well as aspects of the facilitation needing improvement or modification for future lessons (delta). These discussions included addressing facilitator practices, implementation of lesson components, and participant engagement. This time was also allocated for providing teenage teachers a brief overview of the next educational session and assigning lead and co-facilitators.

The intent of this study was to assess the feasibility of program implementation through collection of both quantitative and qualitative data for teenagers and younger youth during the $1^{\text {st }}$ year of implementation to assess the impacts of being an educator and being educated by a teenage teacher, respectively. Participant data collected and assessment tools utilized are detailed in Table 1. Nutrition knowledge was collected using age-appropriate, validated questionnaires both for teenagers (Ruiz et al., 2017) and younger youth (Morris \& ZidenbergCherr, 2002). Self-efficacy for teaching nutrition was measured using a questionnaire originally adapted by Linnell et al. (2016), which was updated to be specific to the SHCP and use the retrospective post-then-pre method (Slattery, 2017). A measure of civic responsibility was also collected from teenagers using the retrospective post-then-pre method and was measured using a reliable questionnaire developed as part of the 4-H Youth Development Program Healthy Living Measures (Furco et al., 1998). Data on vegetable identification and preferences in younger youth were collected using an approach adapted from previous use (Linnell et al., 2016; Scherr et al., 2014) to include taste-testing of six vegetables and open-ended follow-up qualitative prompting in a one-on-one interview style. Dietary intake in teenagers was measured using an online automated multiple-pass 24-hour (ASA24) recall system. Participant demographics were completed by participants' parents, following a method similar to Scherr et al. (2014).

In addition to data collected from participants, previously developed structured observation sheets (Linnell et al., 2016) were utilized during the $1^{\text {st }}$ year to collect observations of lesson implementation (see Appendix). Two trained observers-a graduate and undergraduate student-worked together and used the structured observation sheets at each educational session to measure program fidelity on a 0- to 2-point scale: 0 (not implemented at al/) and 2 (implemented completely as intended) for each lesson and lesson component. Fidelity for each lesson was calculated by totaling the implementation points earned for the observed lesson and then converting the score to a percentage. Fidelity for each lesson component was calculated 


\section{SHCP With Teen Teachers}

by averaging the scores received for that component across all observed lessons and then converting the average score into a percentage.

Table 1. Evaluation Tools and Metrics Collected from Participants During the $\mathbf{1}^{\text {st }}$ Implementation Year

\begin{tabular}{|c|c|c|c|c|}
\hline Group & Metric & $\begin{array}{l}\text { Number } \\
\text { collected pre }\end{array}$ & $\begin{array}{l}\text { Number } \\
\text { collected post }\end{array}$ & Tool source(s) \\
\hline \multirow[t]{5}{*}{$\begin{array}{l}\text { Teenage } \\
\text { teachers }\end{array}$} & Nutrition knowledge & 3 & 3 & $\begin{array}{c}\text { Jones et al. (2015); } \\
\text { Ruiz et al. (2017) }\end{array}$ \\
\hline & $\begin{array}{l}\text { Self-efficacy for } \\
\text { teaching nutrition }\end{array}$ & 3 & 3 & $\begin{array}{c}\text { Linnell et al. (2016) } \\
\text { Slattery (2017) }\end{array}$ \\
\hline & Civic responsibility & 2 & 2 & Furco et al. (1998) \\
\hline & Dietary intake & 1 & 0 & ASA24a \\
\hline & Demographics & 3 & -- & Scherr et al. (2014) \\
\hline \multirow[t]{3}{*}{ Younger youth } & Nutrition knowledge & 7 & 7 & $\begin{array}{c}\text { Morris and } \\
\text { Zidenberg-Cherr } \\
\text { (2002) }\end{array}$ \\
\hline & $\begin{array}{c}\text { Vegetable } \\
\text { identification and } \\
\text { preferences }\end{array}$ & 6 & 4 & $\begin{array}{l}\text { Linnell et al. (2016); } \\
\text { Scherr et al. (2014) }\end{array}$ \\
\hline & Demographics & 8 & -- & Scherr et al. (2014) \\
\hline
\end{tabular}

${ }^{a}$ Automated self-administered 24-hour recall system

The lesson components included opening questions; procedure; sharing, processing, generalizing; follow-up prompting; and concept discovery or introduction. Opening questions prime the participants for the procedure, wherein participants collaborate in small groups to complete structured learning activities (Training Technologies, 1998). The sharing, processing, and generalizing steps then allow participants to reflect on their experiences and analyze realworld application with the assistance of follow-up prompting. Lastly, with concept discovery or introduction, the facilitator ensures that key learning objectives have been met. Observers provided commentary to help provide context for lesson component fidelity score. Observations were collected only when there was enough time to complete the lesson as described in curriculum. Teenage teachers were made aware at the beginning of the study that fidelity observations would be collected throughout the project. However, due to the potential for direct observation to alter implementation fidelity (Breitenstein et al., 2010), specific fidelity scores 


\section{SHCP With Teen Teachers}

were not shared with teenage teachers and observations were taken discreetly. Without disclosing specific scores, to limit the teenage teachers from feeling tested, fidelity to the lesson components was included by project staff in the reflection-on-action discussions mentioned previously. Along with project staff encouraging continuation of practices that resulted in adequate lesson component fidelity, suggestions for improving facilitation of lesson components implemented with inadequate fidelity were also included in discussion. Fidelity observations were not collected for cooking demonstrations due to teenagers' lack of proper food safety and cooking skills which required adult intervention. This adult intervention thus invalidated any fidelity observations that would have been collected on the teenage teachers' ability to facilitate the cooking demonstrations.

All youth had to either already be enrolled in 4-H or enroll in 4-H to take part in the study. All procedures for this study were approved by the University of California, Davis Institutional Review Board.

\section{Program}

The model utilized in this study was developed using the 10 essential elements for successful teenagers-as-teachers programs identified by Lee and Murdock (2001). Table 2 outlines each of the 10 essential elements and indicates how this project met each one. A Cooperative Extension (CE) academic (titled advisor in California) who oversaw the project and facilitated the $1^{\text {st }}$ day of teenager training provided adult support. Additionally, one CE staff member organized the logistics of the project and was present at each day of training and every educational session for both years. For the $1^{\text {st }}$ year, a university researcher provided the $2^{\text {nd }}$ day of teenager training and attended all educational sessions. The researcher also led the reflection-on-action discussions at the end of each educational session for the $1^{\text {st }}$ year and trained the CE staff member to lead reflection discussions during the $2^{\text {nd }}$ year. These reflection-on-action discussions provided ongoing support and additional team building for teenage teachers. The retrospective approach for self-efficacy and civic responsibility measurements also allowed teenagers an opportunity to reflect on their experience and provided personal evaluation. 
SHCP With Teen Teachers

Table 2. Project Alignment With 10 Essential Elements for Successful Teenagers-asTeachers Programs (Lee \& Murdock, 2001)

\begin{tabular}{|c|c|}
\hline Essential element & Evidence in project \\
\hline 1. Dedicated adults & $\begin{array}{l}\text { - Cooperative Extension academic } \\
\text { - Cooperative Extension staff member } \\
\text { - University researcher }\end{array}$ \\
\hline 2. Active recruitment & $\begin{array}{l}\text { - Teenagers recruited from local high schools, other 4-H projects, } \\
\text { and community organizations }\end{array}$ \\
\hline 3. Strong curriculum & $\begin{array}{l}\text { - Discovering Healthy Choices (Linnell et al., 2015) } \\
\text { - Cooking Up Healthy Choices (Brian et al., 2015) }\end{array}$ \\
\hline 4. Initial training & $\begin{array}{l}\text { - 2-day, } 10 \text {-hour training } \\
\text { - Team building, inquiry-based delivery of lessons, and overview of } \\
\text { curricula }\end{array}$ \\
\hline $\begin{array}{l}\text { 5. Ongoing training } \\
\text { and support }\end{array}$ & $\begin{array}{l}\text { - Reflection-on-action sessions using plus/delta format (Linnell et al., } \\
\text { 2016) }\end{array}$ \\
\hline $\begin{array}{l}\text { 6. Attention to } \\
\text { details }\end{array}$ & $\begin{array}{l}\text { - } \text { Cooperative Extension staff member organized all project logistics } \\
\text { - } \text { - } \text { Adult intervention in cooking demonstrations } \\
\text { - } \quad \text { Local and easily accessible location } \\
\text { - } \\
\text { - } \\
\text { - Darticipants and parents chose meeting day and time } \\
\text { other 4-H activities }\end{array}$ \\
\hline $\begin{array}{l}\text { 7. Recognition and } \\
\text { reward }\end{array}$ & $\begin{array}{l}\text { - Reusable water bottle, commemorative 4-H pin, and certificate of } \\
\text { completion } \\
\text { - Paid teenager annual 4-H registration } \\
\text { - Letters of recommendation upon request }\end{array}$ \\
\hline 8. Team building & $\begin{array}{l}\text { - Team building activities in the initial teenager training } \\
\text { - Teenagers supported one another by acting as co-facilitators for } \\
\text { lessons } \\
\text { - Provided written and verbal feedback though reflection sessions }\end{array}$ \\
\hline $\begin{array}{l}\text { 9. Setting teenagers } \\
\text { up for success }\end{array}$ & $\begin{array}{l}\text { - Teenagers praised upon completion of lessons } \\
\text { - } \text { Reflection sessions always ended on something that went well } \\
\text { - Time allocated to setup lesson and familiarize teenage teachers } \\
\text { with lesson materials }\end{array}$ \\
\hline
\end{tabular}




\section{SHCP With Teen Teachers}

Table 2. (continued)

\begin{tabular}{|l|l|}
\hline Essential element & \multicolumn{1}{c|}{ Evidence in project } \\
\hline $\begin{array}{l}\text { 10. Feedback and } \\
\text { evaluation }\end{array}$ & $\begin{array}{l}\text { Feedback from the university researcher, Cooperative Extension } \\
\text { staff member, and each other during the reflection sessions }\end{array}$ \\
& $\begin{array}{l}\text { Retrospective post-then-pre-test self-efficacy and civic engagement } \\
\text { questionnaires }\end{array}$ \\
\hline
\end{tabular}

Teenagers were actively recruited from local organizations and completed an initial training that included development of skills and an overview of the specific curricula to be taught. The curricula used in this project were very strong and included Discovering Healthy Choices (Linnell et al., 2015) and Cooking Up Healthy Choices (Brian et al., 2015), which are research-tested and evidence-based curricula that feature several interactive lessons. The CE staff member provided attention to detail by organizing all project logistics and maintaining consistent communication with all youth and parents. Precautions were taken to ensure the safety of all youth, including adult intervention in cooking demonstrations and supervision during educational sessions. The location was within the youths' community and easily accessible. Participants and parents chose the meeting time, and dates were specifically picked to avoid scheduling conflicts with other 4-H activities. To recognize and reward participants, all youth received a reusable water bottle, commemorative 4- $\mathrm{H}$ pin, and certificate of completion for participating in the project. For teenage teachers, the annual $4-\mathrm{H}$ registration fee $(\$ 40)$ was also paid and the CE staff member offered to write letters of recommendation for the teenage teachers upon request.

\section{Results}

All data shown are from the $1^{\text {st }}$ implementation year. Although low participation was expected given that new 4-H projects in the implementation area traditionally have taken a few years to gain popularity, the sample sizes were lower than anticipated resulting in underpowered data analyses. Five teenagers (aged 14 to 15 years) were recruited and trained as cross-age teachers. One teenager dropped out of the project immediately following the initial training and another did not consent for data collection, leaving three teenage teachers included in data collection. Eight younger youth (aged 9 to 13 years) were recruited and consented to data collection. Additional recruitment measures beyond those previously mentioned were not taken as this method was standard procedure for the partner 4-H group and part of feasibility testing. As shown in Table 3, participant ages were evenly distributed, and most participants were girls. 
Journal of Youth Development | http://jyd.pitt.edu/ | Vol. 15 Issue 5 DOI 10.5195/jyd.2020.761

SHCP With Teen Teachers

Participation and attendance were inconsistent for younger youth, with only five regularly attending educational sessions.

Table 3. Characteristics of $1^{\text {st }}$-Year Participants $(n=11)$

\begin{tabular}{|c|c|c|}
\hline \multicolumn{2}{|l|}{ Characteristic } & \multirow{2}{*}{$\begin{array}{l}\text { Participants } \\
\qquad n(\%) \\
2(18.2)\end{array}$} \\
\hline Age (years) & 9 & \\
\hline & 10 & $1(9.1)$ \\
\hline & 11 & $3(27.3)$ \\
\hline & 13 & $2(18.2)$ \\
\hline & 14 & $1(9.1)$ \\
\hline & 15 & $2(18.2)$ \\
\hline \multirow[t]{2}{*}{ Sex } & Girls & $8(72.7)$ \\
\hline & Boys & $3(27.3)$ \\
\hline \multirow[t]{3}{*}{ Ethnicity/race } & African American/Black & $2(18.2)$ \\
\hline & Caucasian/White & $6(54.5)$ \\
\hline & Multiethnic & $3(27.3)$ \\
\hline \multirow[t]{3}{*}{ Household income } & $\$ 59,999$ or less & $4(36.4)$ \\
\hline & $\$ 60,000-\$ 99,999$ & $3(27.3)$ \\
\hline & $\$ 100,000$ or more & $4(36.4)$ \\
\hline \multirow[t]{4}{*}{$\begin{array}{l}\text { Primary caregiver's } \\
\text { education }\end{array}$} & $\begin{array}{l}\text { Vocational/technical } \\
\text { training or some college }\end{array}$ & $4(36.4)$ \\
\hline & Associate degree & $5(45.5)$ \\
\hline & Bachelor's degree & $1(9.1)$ \\
\hline & Postgraduate degree & $1(9.1)$ \\
\hline
\end{tabular}




\section{SHCP With Teen Teachers}

As previously mentioned, data were not collected for the $2^{\text {nd }}$ implementation year, as the primary focus for that year was on whether the program could continue without additional support. However, all participating teenage teachers from the $1^{\text {st }}$ year returned in addition to two new teenage teachers, one of whom was a younger youth from the $1^{\text {st }}$ year. Participation and attendance were again inconsistent for younger youth during the $2^{\text {nd }}$ implementation year, with only two of five consented youth regularly attending educational sessions. The other three younger youth during this phase joined half-way through the program implementation and did not provide demographic information.

Although a plethora of assessment data were collected, most could not be analyzed due to insufficient sample sizes and inconsistent attendance. However, positive youth outcomes resulting from participation in the SHCP have previously been observed with a program fidelity threshold of $80 \%$ (Bergman et al., 2018). For this project, the overall average program fidelity was $45 \%$. Figure 1 shows fidelity for each lesson. Only Lesson 2.1 met the $80 \%$ fidelity goal, and it should be noted that this lesson was the lesson demonstrated in the in-depth $2^{\text {nd }}$-day facilitation training during the initial training. Lessons 3.1 and 7.1 were the next highest but reached only $70 \%$ fidelity to the curriculum. All other lessons were facilitated with $60 \%$ or lower fidelity.

Figure 1. Fidelity to the Discovering Healthy Choices (Linnell et al., 2015) Curriculum by Lesson in the $1^{\text {st }}$ Year

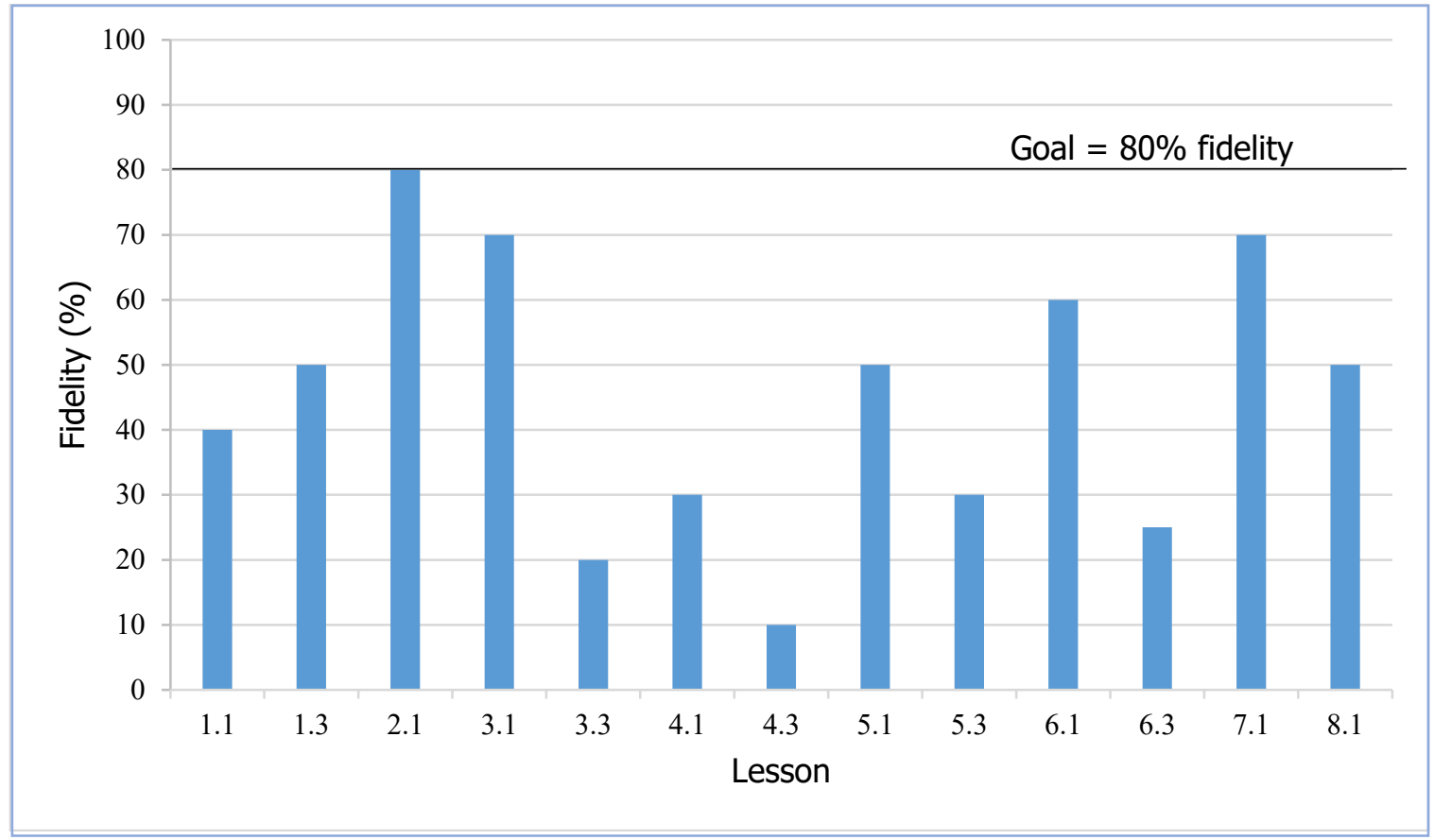




\section{SHCP With Teen Teachers}

Regarding fidelity for each lesson component (Figure 2), procedure was the only component implemented at or above the $80 \%$ fidelity goal $(84.6 \%$ average fidelity). Commentary for this component indicated that teenage teachers dedicated ample time for the procedure and followed the prescribed steps in the curriculum exactly. The time dedicated to the procedure deducted time from other components, and the low fidelity scores for the other componentsparticularly follow-up prompting and concept discovery or introduction-was attributed to less time devoted to those components.

Figure 2. Average Fidelity to the Discovering Healthy Choices (Linnell et al., 2015) Curriculum by Lesson Component in the $1^{\text {st }}$ Year

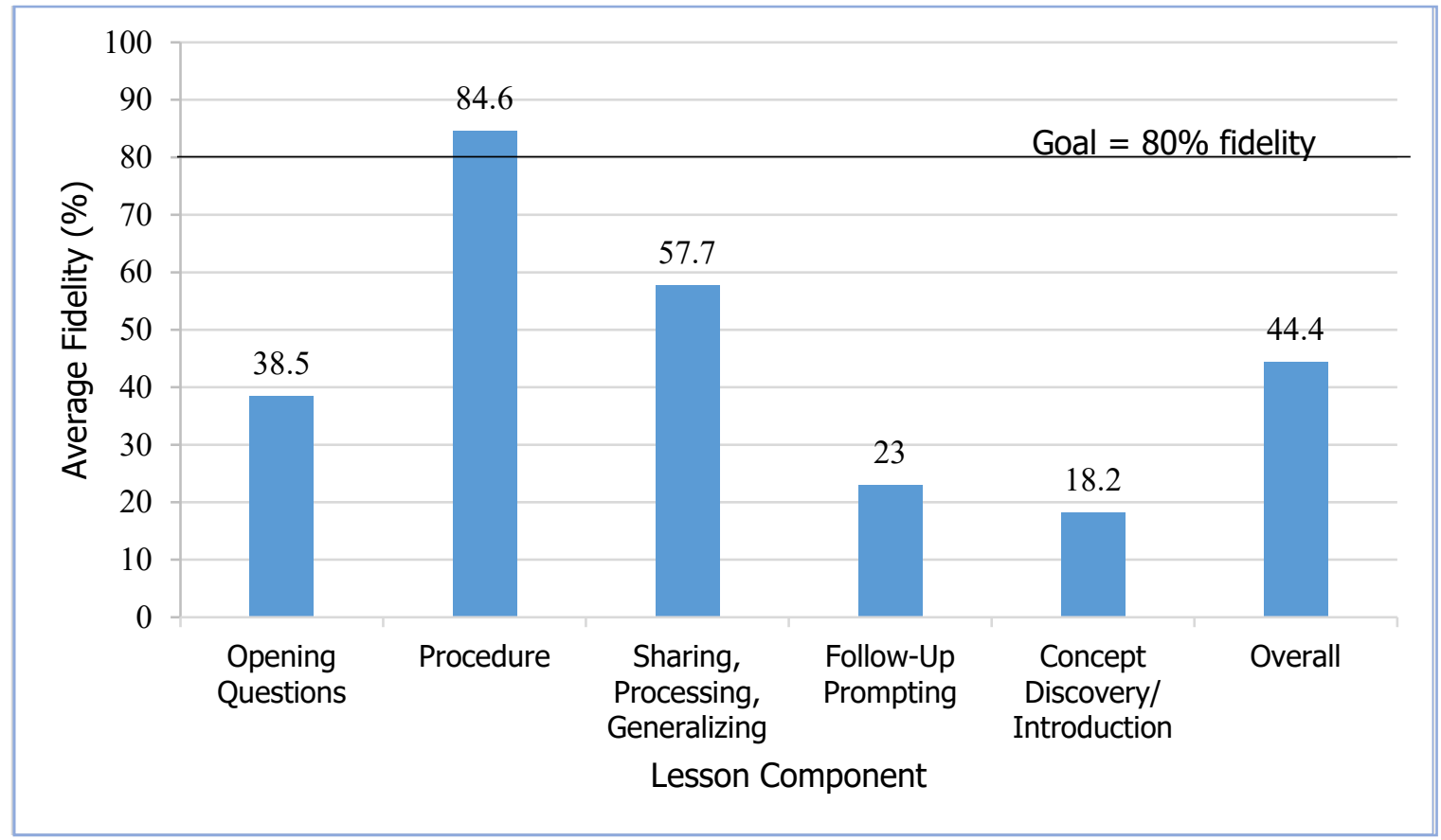

\section{Discussion}

The SHCP is traditionally implemented as a school-based intervention, but a goal at the time of its development was also for it to be implemented within $4-\mathrm{H}$. This project served as a feasibility study to determine whether the SHCP could be adapted and effectively implemented within 4-H with teenagers taking the role of cross-age teachers for younger youth. 4- $\mathrm{H}$ has a history of being predominantly Caucasian and has a goal to engage more diverse youth, which was a relative success with this project during the $1^{\text {st }}$ year. Additionally, teenage teachers enjoyed participating in this project, as evidenced by all returning for the $2^{\text {nd }}$ implementation year, but 


\section{SHCP With Teen Teachers}

lack of younger youth participation and attendance considerably affected the potential of this project and the results that could be presented. There were challenges with recruitment and retention due to youth participation in additional 4-H clubs and projects and a variety of other activities that took priority, so the sample size of this study was quite small. Because this limitation prevented collection of meaningful data on participant outcomes as well as analyses that could be completed, it limits generalizability of the results. Perhaps a new 4-H project of this nature would be better-suited to participants with fewer outside commitments and those new to 4-H. Additionally, the time and day, even though selected by parents and youth, seemed to limit regular attendance. Other $4-\mathrm{H}$ projects involving nutrition that have been successful were implemented through existing after-school programs at elementary schools (Bolshakova, Gieng, \& Sidhu, 2018; Bolshakova, Gieng, Sidhu, et al., 2018; Smith, 2011). This allowed for the location to be convenient for participants and the timing to be advantageous to youth and parents.

Teenage teachers were able to deliver Lesson 2.1 with adequate fidelity (80\%), however this was the lesson that was modeled for teenage teachers during the initial training, in which indepth facilitation tips were also provided. Although overall fidelity was low, teenage teachers were able to effectively facilitate the procedure phase of the lessons with relatively high average fidelity (84.6\%). This may be because the procedure portion includes step-by-step instructions for facilitation. Conversely, teenage teachers had the poorest fidelity for the followup prompting (23\%) and the concept discovery or introduction (18.2\%) phases. These two steps are the most challenging to facilitate, but also are important steps in experiential pedagogy to ensure that concepts are learned (Training Technologies, 1998).

Adequate fidelity is just one of the factors that can affect outcomes, with effective implementation generally being associated with better outcomes (Bergman et al., 2018; Durlak \& DuPre, 2008). Fidelity does not have to be $100 \%$, so there is room for adaptation (Century et al., 2010; Durlak \& DuPre, 2008; Harn et al., 2013), but should be at least $80 \%$ for the SHCP given the curricula structure and previous findings (Bergman et al., 2018). The low fidelity observed in this project suggests that teenage teachers may not have been fully prepared to act as facilitators for all lessons and that additional facilitation training may improve future lesson delivery. Other studies of this nature have provided varying lengths of time allocated for the initial training ranging from 6 hours to several days (Arnold et al., 2016; Bolshakova, Gieng, Sidhu, et al., 2018; Edwards et al., 2006; Smith, 2011; Weybright et al., 2016). 


\section{SHCP With Teen Teachers}

One curriculum designed to train teenage teachers that was developed for use in 4- $\mathrm{H}$ is Youth Advocates for Health (YA4-H!), which focuses on teaching professional development for teenagers (Arnold et al., 2016; Flesch et al., 2015). YA4-H! can be purchased through 4-H and does not provide specific content knowledge for the program teenagers will be teaching, so it can be adapted for a variety of programs. The YA4-H! program has been widely used and shown to improve confidence, comfort, applicable skills, and perceived subject knowledge in trained teenage teachers (Arnold et al., 2016; Weybright et al., 2018). Along with insufficient facilitation training, it is hypothesized that a lack of content knowledge could have been a hindrance in the current project. Teenagers acted as cross-age teachers in another recent intervention that was designed similarly to the present study and included nutrition content training in addition to using YA4-H! (Weybright et al., 2016; Weybright et al., 2018). This approach observed increases in reported nutrition knowledge and positive behaviors that were attributed to being successful in a teenage teacher role (Weybright et al., 2016; Weybright et al., 2018). Although other approaches have been successful at implementing nutrition education programming utilizing teenagers as cross-age teachers, the same protocol may be insufficient for SHCP curricula because the content supersedes general nutrition.

Practitioners should consider measuring fidelity when implementing multi-component programming. Measuring fidelity for individual components of a program or curriculum implementation can be helpful in identifying possible explanations for unexpected outcomes, especially when implementing an existing program in a new context. Additionally, fidelity measurement of individual components allows for targeted training and improvement of practice over time.

\section{Future Directions}

The curricula of the SHCP are quite comprehensive and their implementation has been found to be most successful with adequately knowledgeable and confident educators (Linnell et al., 2016). Due to this, the SHCP has been implemented with the CalFresh Healthy Living, University of California program using trained adult educators. The background content for each module of the SHCP curricula is fairly limited and may not provide enough depth for those that do not have ample content knowledge. Findings from the present study provide rationale and impetus for more extensive education and training for teenage teachers implementing the SHCP. The training should incorporate more opportunities for teenage teachers to engage in lesson delivery and teacher skill-building as well as gaining applicable subject matter 


\section{SHCP With Teen Teachers}

knowledge. Future directions include the development of a two-tiered, cross-age-teaching training model, wherein college undergraduate interns will be trained to educate teenagers in food literacy and cross-age teaching methodology. All education will be completed within existing after-school programs. College interns will use a newly developed curriculum, Teens CAN: Comprehensive Food Literacy in Cooking, Agriculture, and Nutrition (Ruiz et al., 2019). Teens CAN differs in extent and content from other curricula in that it focuses on the food system as a whole, rather than gardening, and teaches cooking skills and food safety. Additionally, the curriculum also includes specific content on nutrition and nutrients of concern for adolescents. This approach will include a 3-day training and provide background knowledge in an engaging way using modeling, role-playing, and reflection training to prepare for crossage teaching. It is anticipated that knowledge gained from actively engaging in Teens CAN lessons, or another age-appropriate comprehensive nutrition curriculum, and more targeted training will allow future teenage teachers facilitating SHCP curricula to achieve higher fidelity.

\section{Acknowledgements}

Funding was provided in part by UC ANR Competitive Grant \#15-3723 and USDA NIFA, Hatch project 221082. The authors would like to thank Jill Simmons, Dr. Martin Smith, Dr. Jessica Linnell, Britt Robinson, Nader Hamdi, Roxanna Tamayo, Hyun Hee (Hanee) Park, Michelle Chellino, and the parents and youth who participated in the project.

\section{References}

Ajala, O., Mold, F., Boughton, C., Cooke, D., \& Whyte, M. (2017). Childhood predictors of cardiovascular disease in adulthood. A systematic review and meta-analysis. Obesity Reviews, 18(9), 10611070. https://doi.org/10.1111/obr.12561

Arnold, M. E., Flesch, J. M., Ashton, C., Black, L., Brody, B., Hosty, M., \& Northway, S. (2016). YA4-H! Youth advocates for health: Impact of a 4-H teens-as-teachers program. Journal of Extension, 54(6). https://www.joe.org/joe/2016december/rb5.php

ASA24, the automated self-administered recall system. Retrieved from https://asa24.nci.nih.gov/ Bandura, A. (1986). Social foundations of thought and action: A social cognitive theory. Englewood Cliffs, NJ: Prentice Hall.

Banfield, E. C., Liu, Y., Davis, J. S., Chang, S., \& Frazier-Wood, A. C. (2016). Poor adherence to US dietary guidelines for children and adolescents in the national health and nutrition examination 
Journal of Youth Development | http://jyd.pitt.edu/ | Vol. 15 Issue 5 DOI 10.5195/jyd.2020.761

\section{SHCP With Teen Teachers}

survey population. Journal of the Academy of Nutrition and Dietetics, 116(1), 21-27.

https://doi.org/10.1016/j.jand.2015.08.010

Bergman, J. J., Linnell, J. D., Scherr, R. E., Ginsburg, D. C., Brian, K. M., Carter, R., Donohue, S., Klisch, S., Lawry-Hall, S., Pressman, J., Soule, K., \&Zidenberg-Cherr, S. (2018). Feasibility of implementing a school nutrition intervention that addresses policies, systems, and environment. Journal of Extension, 56(1).

Bolshakova, V. L. J., Gieng, J., \& Sidhu, C. S. (2018). Teens-as-teachers nutrition program increases interest in science among schoolchildren and fosters self-efficacy in teens. California Agriculture, 72(2), 135-143. https://doi.org/10.3733/ca.2018a0016

Bolshakova, V. L. J., Gieng, J., Sidhu, C. S., Vollinger, M., Gimeno, L., \& Guild, J. (2018). Teens as teachers in the garden: Cultivating a sustainable model for teaching healthy living. Journal of Youth Development, 13(3), 111-135. https://doi.org/10.5195/jyd.2018.621

Breitenstein, S. M., Gross, D., Garvey, C. A., Hill, C., Fogg, L., \& Resnick, B. (2010). Implementation fidelity in community-based interventions. Research in Nursing \& Health, 33(2), 164-173. https://doi.org/10.1002/nur.20373

Brian, K. M., Linnell, J. D., \& Zidenberg-Cherr, S. (2015). Cooking Up Healthy Choices. Davis: University of California.

Century, J., Rudnick, M., \& Freeman, C. (2010). A framework for measuring fidelity of implementation: A foundation for shared language and accumulation of knowledge. American Journal of Evaluation, 31(2), 199-218. https://doi.org/10.1177/1098214010366173

Durlak, J. A., \& DuPre, E. P. (2008). Implementation matters: A review of research on the influence of implementation on program outcomes and the factors affecting implementation. American Journal of Community Psychology, 41(3-4), 327-350. https://doi.org/10.1007/s10464-008-9165-0

Edwards, H. C., Safrit, R. D., Gliem, J. A., \& Rudd, C. (2006). Knowledge and attitudinal impacts upon teen volunteers teaching younger youth in a community-based obesity and overweight prevention education program. The International Journal of Volunteer Administration, 14, 41-52.

Faienza, M. F., Wang, D. Q., Fruhbeck, G., Garruti, G., \& Portincasa, P. (2016). The dangerous link between childhood and adulthood predictors of obesity and metabolic syndrome. Internal Emergency Medicine, 11(2), 175-182. https://doi.org/10.1007/s11739-015-1382-6

Fetter, D. S., Scherr, R. E., Linnell, J. D., Dharmar, M., Schaefer, S. E., \& Zidenberg-Cherr, S. (2018). Effect of the Shaping Healthy Choices Program, a multicomponent, school-based nutrition intervention, on physical activity intensity. Journal of the American College of Nutrition, 376), 472-478. https://doi.org/10.1080/07315724.2018.1436477

Flesch, J. M., Lile, J. R., \& Arnold, M. E. (2015). YA4-H! Youth advocates for health: Teens as teachers. Journal of Youth Development, 10(2), 121-124. https://doi.org/10.5195/jyd.2015.414 
Journal of Youth Development | http://jyd.pitt.edu/ | Vol. 15 Issue 5 DOI 10.5195/jyd.2020.761

\section{SHCP With Teen Teachers}

Fosnot, C. T. (2013). Constructivism: Theory, perspectives, and practice ( $2^{\text {nd }}$ ed.). Teachers College Press.

Fryar, C. D., Carroll, M. D., \& Ogden, C. L. (2018). Prevalence of overweight, obesity, and severe obesity among children and adolescents aged 2-19 years: United States, 1963-1965 through 2015-2016. National Center for Health Statistics. https://www.cdc.gov/nchs/data/hestat/obesity child 13 14/obesity child 13 14.htm

Furco, A., Muller, P., \& Ammon, M. (1998). The civic responsibility survey. Service-Learning Research Center, University of California, Berkley.

Gearing, R. E., El-Bassel, N., Ghesquiere, A., Baldwin, S., Gillies, J., \& Ngeow, E. (2011). Major ingredients of fidelity: A review and scientific guide to improving quality of intervention research implementation. Clinical Psychology Review, 31(1), 79-88. https://doi.org/10.1016/j.cpr.2010.09.007

Harn, B., Parisi, D., \& Stoolmiller, M. (2013). Balancing fidelity with flexibility and fit: What do we really know about fidelity of implementation in schools? Exceptional Children, 79(3), 181-193. https://doi.org/10.1177/001440291307900204

Hayes, D., Contento, I. R., \& Weekly, C. (2018). Position of the Academy of Nutrition and Dietetics, Society for Nutrition Education and Behavior, and School Nutrition Association: Comprehensive nutrition programs and services in schools. Journal of the Academy of Nutrition and Dietetics, 118(5), 913-919. https://doi.org/10.1016/i.jand.2018.03.005

Jones, A. M., Lamp, C., Neelon, M., Nicholson, Y., Schneider, C., Wooten Swanson, P., \& ZidenbergCherr, S. (2015). Reliability and validity of nutrition knowledge questionnaire for adults. Journal of Nutrition Education and Behavior, 471), 69-74. https://doi.org/10.1016/j.jneb.2014.08.003

Kim, J., Lee, I., \& Lim, S. (2017). Overweight or obesity in children aged 0 to 6 and the risk of adult metabolic syndrome: A systematic review and meta-analysis. Journal of Clinical Nursing, 26(2324), 3869-3880. https://doi.org/10.1111/jocn.13802

Kolb, D. A. (2015). Experiential learning: Experience as the source of learning and development (2 ${ }^{\text {nd }}$ ed.). Upper Saddle River, New Jersey: Pearson Education.

Lee, F. C. H., \& Murdock, S. (2001). Teenagers as teachers programs: Ten essential elements. Journal of Extension, 39(1).

Linnell, J. D., Smith, M. H., Briggs, M., Brian, K. M., Scherr, R. E., Dharmar, M., \& Zidenberg-Cherr, S. (2016). Evaluating the relationships among teacher characteristics, implementation factors, and student outcomes of children participating in an experiential school-based nutrition program. Pedagogy in Health Promotion, 2(4), 256-265. https://doi.org/10.1177/2373379916649603

Linnell, J. D., Smith, M. H., \& Zidenberg-Cherr, S. (2015). Discovering Healthy Choices. Davis: University of California. 


\section{SHCP With Teen Teachers}

Morris, J. L., \& Zidenberg-Cherr, S. (2002). Garden-enhanced nutrition curriculum improves fourth-grade school children's knowledge of nutrition and preferences for some vegetables. Journal of the American Dietetic Association, 102(1), 91-93. https://doi.org/10.1016/s0002-8223(02)90027-1

Mowbray, C. T., Holter, M. C., Teague, G. B., \& Bybee, D. (2003). Fidelity criteria: Development, measurement, and validation. American Journal of Evaluation, 24(3), 315-340. https://doi.org/10.1177/109821400302400303

Murdock, S. W., Lee, F. C. H., \& Paterson, C. A. (2003). The role of cross-age teaching in supporting adolescent development. 4-H Center for Youth Development, University of California. http://4h.ucanr.edu/files/1308.pdf

National 4-H Council. Retrieved from https://4-h.org/about/what-is-4-h/

Ruiz, L. D., Howe, L., Holland, D., Brian, K. M., \& Scherr, R. E. (2019). Development of an innovative food literacy curriculum focused on agriculture, nutrition, and cooking for high school-aged adolescents. Current Developments in Nutrition, 3(S1). 1464.

Ruiz, L. D., Jones, A. M., \& Scherr, R. E. (2017). Validity and reliability of a nutrition knowledge questionnaire for adolescents. The FASEB Journal, 31(S1), 957-953. https://doi.org/10.1096/fasebj.31.1 supplement.957.3

Scherr, R. E., Linnell, J. D., Dharmar, M., Beccarelli, L. M., Bergman, J. J., Briggs, M., Brian, K. M., Feenstra, G., Hillhouse, J. C., Keen, C. L., Ontai, L. L., Schaefer, S. E., Smith, M. H., Spezzano, T., Steinberg, F. M., Sutter, C., Young, H. M., \& Zidenberg-Cherr, S. (2017). A multicomponent, school-based intervention, the shaping healthy choices program, improves nutrition-related outcomes. Journal of Nutrition Education and Behavior, 49(5), 368-379 e361. https://doi.org/10.1016/j.jneb.2016.12.007

Scherr, R. E., Linnell, J. D., Smith, M. H., Briggs, M., Bergman, J. J., Brian, K. M., Dharmar, M., Feenstra, G., Hillhouse, J. C., Keen, C. L., Nguyen, L., M., Nicholson, Y., Ontai, L. L., Schaefer, M. H., Spezzano, T., Steinberg, F. M., Sutter, C., Wright, J. E., Young, H. M., \& Zidenberg-Cherr, S. (2014). The shaping healthy choices program: Design and implementation methodologies for a multicomponent, school-based nutrition education intervention. Journal of Nutrition Education and Behavior, 46(6), e13-21. https://doi.org/10.1016/j.jneb.2014.08.010

Shanahan, A. (2015). The Relationship between cross-age teaching and social \& emotional learning. University of Minnesota Extension.

Singh, A. S., Mulder, C., Twisk, J. W., van Mechelen, W., \& Chinapaw, M. J. (2008). Tracking of childhood overweight into adulthood: A systematic review of the literature. Obesity Reviews, g(5), 474-488. https://doi.org/10.1111/j.1467-789X.2008.00475.x

Slattery, C. (2017). An exploration of leadership development through action inquiry and its impact on educator self-efficacy. National University. 
Journal of Youth Development | http://jyd.pitt.edu/ | Vol. 15 Issue 5 DOI 10.5195/jyd.2020.761

\section{SHCP With Teen Teachers}

Smetana, J. G., Campione-Barr, N., \& Metzger, A. (2006). Adolescent development in interpersonal and societal contexts. Annual Review of Psychology, 57, 255-284.

https://doi.org/10.1146/annurev.psych.57.102904.190124

Smith, L. H. (2011). Piloting the use of teen mentors to promote a healthy diet and physical activity among children in Appalachia. Journal for Specialists in Pediatric Nursing, 16(1), 16-26. https://doi.org/10.1111/j.1744-6155.2010.00264.x

Taylor, J. C., Zidenberg-Cherr, S., Linnell, J. D., Feenstra, G., \& Scherr, R. E. (2017). Impact of a multicomponent, school-based nutrition intervention on students' lunchtime fruit and vegetable availability and intake: A pilot study evaluating the shaping healthy choices program. Journal of Hunger \& Environmental Nutrition, 13(3), 415-428.

https://doi.org/10.1080/19320248.2017.1374899

Thomson, J. L., Tussing-Humphreys, L. M., Goodman, M. H., \& Landry, A. S. (2019). Diet quality in a nationally representative sample of American children by sociodemographic characteristics. The American Journal of Clinical Nutrition, 109(1), 127-138.

Training Technologies for Experiential Learning Activities. (1998). (2 ${ }^{\text {nd }}$ ed., Vol. 21): Jossey-Bass/Pfeiffer. Weybright, E. H., Hrncirik, L. M., White, A. J., Cummins, M. M., Deen, M. K., \& Calodich, S. (2016). "I felt really respected and I know she felt respected too": Using youth-adult partnerships to promote positive youth development in 4-H youth. Journal of Human Sciences and Extension, 4(3), 93-110.

Weybright, E. H., Martinez, A. D., Varrella, G., Deen, M. K., \& Wright, K. (2018). Teens as teachers: Positive outcomes and recommendations for promoting healthy nutrition in adolescents. Journal of Youth Development, 13(3), 43-60. https://doi.org/10.5195/jyd.2018.595

Worker, S. M., Iaccopucci, A. M., Bird, M., \& Horowitz, M. (2018). Promoting positive youth development through teenagers-as-teachers programs. Journal of Adolescent Research, 34(1), 30-54. https://doi.org/10.1177/0743558418764089 
SHCP With Teen Teachers

Appendix

Observation Tool for Implementation of [Curriculum Name]

Observer

Educator

Date

Activity [\#] - [Title]

\section{Program Fidelity}

\begin{tabular}{|c|c|c|}
\hline Curriculum Session & Program Fidelity & Notes \\
\hline $\begin{array}{l}\text { Opening Questions } \\
\text { Time started: } \\
\text { Time ended: }\end{array}$ & $\begin{array}{l}\text { Asked opening questions } \\
\begin{aligned} & \square \text { Did not do } \\
& \square \text { Partially delivered according to } \\
& \text { curriculum } \\
& \square \text { Fully delivered according to } \\
& \text { curriculum }\end{aligned}\end{array}$ & \\
\hline $\begin{array}{l}\text { Procedure (Experiencing) } \\
\text { Time started: } \\
\text { Time ended: }\end{array}$ & 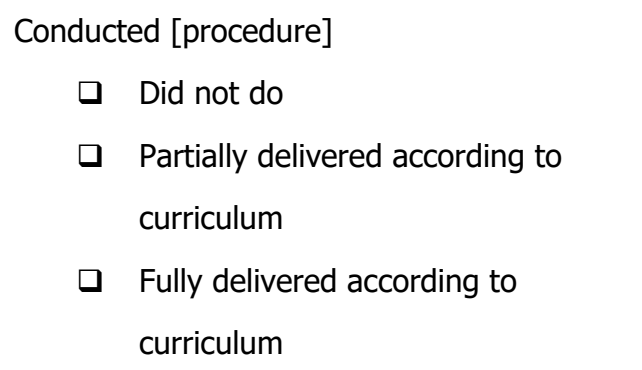 & \\
\hline $\begin{array}{l}\text { Sharing, Processing and } \\
\text { Generalizing } \\
\text { Time started: } \\
\text { Time ended: }\end{array}$ & $\begin{array}{l}\text { Youth shared and discussed their [product of } \\
\text { the procedure] and what they learned } \\
\square \text { Did not do } \\
\text { Partially delivered according to } \\
\text { curriculum } \\
\text { Fully delivered according to } \\
\text { curriculum }\end{array}$ & \\
\hline $\begin{array}{l}\text { Concept of Term } \\
\text { Discovery/Introduction } \\
\text { Time started: } \\
\text { Time ended: }\end{array}$ & $\begin{array}{l}\text { Concepts and terms such as [primary } \\
\text { concepts] were discovered by the youth or } \\
\text { introduced by the facilitator } \\
\square \text { Did not do } \\
\square \text { Partially delivered according to } \\
\text { curriculum } \\
\square \quad \text { Fully delivered according to } \\
\text { curriculum }\end{array}$ & \\
\hline
\end{tabular}

